University of Wollongong

Research Online

Faculty of Engineering and Information

Faculty of Engineering and Information

Sciences - Papers: Part A

Sciences

$1-1-2012$

\title{
Distortion behavior of a heavy hydro turbine blade casting during forced air cooling in normalizing treatment process
}

\author{
Hailiang Yu \\ University of Wollongong, hailiang@uow.edu.au \\ Jinwu Kang \\ Tsinghua University \\ T J. Wang \\ Tsinghua University \\ J A. Ma \\ Tsinghua University \\ Y Y. Hu \\ Tsinghua University
}

See next page for additional authors

Follow this and additional works at: https://ro.uow.edu.au/eispapers

Part of the Engineering Commons, and the Science and Technology Studies Commons

Research Online is the open access institutional repository for the University of Wollongong. For further information contact the UOW Library: research-pubs@uow.edu.au 


\title{
Distortion behavior of a heavy hydro turbine blade casting during forced air cooling in normalizing treatment process
}

\begin{abstract}
Distortion behavior of blade castings in heat treatment process determines their geometrical accuracy, and improper control of it may result in additional repair, shape righting, or even rejection. This article presents a novel approach for discovering the distortion behavior of heavy blade castings during heat treatment process in production. Real-time measurements of distortion and temperature field of a heavy hydro turbine blade casting weighted 17 ton during forced air cooling in normalizing treatment process were carried out by using deformation measurement instruments and an infrared thermal imaging camera. The distortion processes of the typical locations of blade and the temperature field of the blade were obtained. One corner on the blade outlet edge side exhibits variation of distortion with two peaks and a valley. The range reaches $97 \mathrm{~mm}$ and the final distortion value is $76 \mathrm{~mm}$. The maximum temperature difference on blade surface reaches $460^{\circ} \mathrm{C}$ after $80 \mathrm{~min}$ of cooling. Influences of thermal stress and phase transformation stress on the distortion of the blade were elucidated and discussed. The results are of great significance for the understanding and control of the distortion behavior of hydro turbine blades in heat treatment.
\end{abstract}

\section{Keywords}

forced, air, cooling, normalizing, distortion, behavior, heavy, hydro, treatment, turbine, process, blade, casting, during

\section{Disciplines}

Engineering | Science and Technology Studies

\section{Publication Details}

Yu, H., Kang, J., Wang, T. J., Ma, J. A., Hu, Y. Y., Huang, T., Wang, S. B., Wu, Y., Zhang, C. C., Dai, Y. \& Li, P. (2012). Distortion behavior of a heavy hydro turbine blade casting during forced air cooling in normalizing treatment process. Journal of Materials Engineering and Performance, 21 (1), 55-61.

\section{Authors}

Hailiang Yu, Jinwu Kang, T J. Wang, J A. Ma, Y Y. Hu, Tianyou Huang, S B. Wang, Y Wu, C C. Zhang, YanTao Dai, and P Li 


\title{
Distortion Behavior of a Heavy Hydro Turbine Blade Casting During Forced Air Cooling in Normalizing Treatment Process
}

\author{
Hai-liang Yu, Jin-wu Kang, Tian-jiao Wang, Ji-yu Ma, Yong-yi Hu, Tian-you Huang, Shi-bin Wang, \\ Ying Wu, Cheng-chun Zhang, Yan-tao Dai, and Peng Li
}

(Submitted December 28, 2009; in revised form August 26, 2010)

\begin{abstract}
Distortion behavior of blade castings in heat treatment process determines their geometrical accuracy, and improper control of it may result in additional repair, shape righting, or even rejection. This article presents a novel approach for discovering the distortion behavior of heavy blade castings during heat treatment process in production. Real-time measurements of distortion and temperature field of a heavy hydro turbine blade casting weighted 17 ton during forced air cooling in normalizing treatment process were carried out by using deformation measurement instruments and an infrared thermal imaging camera. The distortion processes of the typical locations of blade and the temperature field of the blade were obtained. One corner on the blade outlet edge side exhibits variation of distortion with two peaks and a valley. The range reaches $97 \mathrm{~mm}$ and the final distortion value is $76 \mathrm{~mm}$. The maximum temperature difference on blade surface reaches $460^{\circ} \mathrm{C}$ after $80 \mathrm{~min}$ of cooling. Influences of thermal stress and phase transformation stress on the distortion of the blade were elucidated and discussed. The results are of great significance for the understanding and control of the distortion behavior of hydro turbine blades in heat treatment.
\end{abstract}

Keywords distortion, hydro turbine blade casting, martensitic stainless steel, normalizing, real-time measurement

\section{Introduction}

Heavy steel castings are key components widely used in power plants, metallurgical industries, etc. Deformation and defects might appear in castings in production because of thermal stress, transformation stress, etc., especially in blade castings with complex structure and significant cross-section difference (Ref 1). Once severe deformation or crack appears, some additional repair and shape righting are needed, even they might be rejected.

Blade is one of the main components of hydro turbines, whose quality determinates the efficiency, contribution, cavitation performance, and service life of turbine units. Owing to huge requirement of turbine blades in market, discovering and controlling the distortion behavior of blades during casting and heat treatment processes are of long-term significances and industrial application values. Casting technologies for blades

Hai-liang Yu, Jin-wu Kang, Tian-jiao Wang, Ji-yu Ma, Yong-yi Hu, and Tian-you Huang, Key Laboratory for Advanced Materials Processing Technology of Ministry of Education, Department of Mechanical Engineering, Tsinghua University, Beijing 100084, China; Hai-liang Yu, State Key Laboratory of Rolling and Automation, Northeastern University, Shenyang 110004, China; and Shi-bin Wang, Ying Wu, Cheng-chun Zhang, Yan-tao Dai, and Peng Li, Harbin Electric Machinery Company Limited, Harbin 150040, China. Contact e-mails: yuhailiang@mail.tsinghua.edu.cn, yuhailiang1980@tom.com, yuhl@ral.neu.edu.cn and kangjw@mail.tsinghua.edu.cn.

have been given universal attentions by countries (Ref 2). The casting process of a turbine blade in Three Gorges Project was studied by $\mathrm{Wu}$ (Ref 3 ), and the fluid field in filling process, temperature, and stress fields during solidification were obtained by using the numerical simulation method. The thermal stress analysis of a blade during casting was also simulated by Li and Wang (Ref 4), and some technical ways were proposed for improvement of the geometrical accuracy of blade castings. A FDM/FEM system was used to simulate the stress field and the distortion behavior of a hydro turbine blade casting by Liu et al. (Ref 5), and results show large residual distortion with more than $60.9 \mathrm{~mm}$ at one corner of the blade. The deformation behavior of a heavy hydro turbine blade casting in casting process was simulated using the FDM/FEM system by Zhang et al. (Ref 6), and a loop method was employed to calculate the inverse deformation. The thermomechanical behavior of a propeller casting in sand casting process was simulated using the finite element method by Lee and Lee (Ref 7), and the effect of shake-out time and shake-out method on the deformation of the propeller casting was investigated, and sequential shake-out method was more efficient than simultaneous shake-out method for the control of the distortion of the propeller casting. A thermo-mechanical-metallurgical model of both forging and cooling stages was developed by Bruschi and Ghiotti (Ref 8), which was used in simulation of geometrical distortions of hot forged turbine blades. Meanwhile, the reverse methodology of adjusting featured parameters were employed for the design and optimization of casting and heat treatment processes based on numerical results (Ref 6, 9). Numerical methods were used for analyzing temperature field, stress field, deformation, etc., of castings in casting and heat treatment processes, and some interesting results were obtained. However, the boundary conditions are difficultly determined in normalizing treatment process of blades, e.g., the 
thermal conductivity coefficient on blade surface when using forced air cooling. Hence, accurately predicting the distortion behavior of blades only using numerical methods is very difficult. Meanwhile, knowledge of the distortion behavior of heavy blade castings in normalizing treatment process by experimental methods has not yet been obtained before.

The ZG0Cr13Ni4Mo alloy is a kind of martensitic stainless steel, which is widely used in hydro, steam, and gas turbines for its special performances during casting, forging, welding, mechanical working, anti-corroding, etc. (Ref 10, 11). The ascast microstructure of blade is of high hardness, poor plasticity, and high residual stress. Heat treatment must be carried out before putting into application. In normalizing treatment process, the distortion at blade corner often occurs for thermal stress and transformation stress. The control of the distortion behavior of blades is helpful for the reduction of machining allowance, and the improvement of material utilization finally. In this article, the authors present a novel approach for real-time measurement of the distortion of blade casting during forced air cooling by using deformation measurement instruments. And the temperature field of blade was measured by means of an infrared thermal imaging camera. Influences of the thermal stress and the transformation stress on the distortion process were also analyzed.

\section{Experimental}

The distortion and temperature fields of a hydro turbine blade casting in normalizing treatment process were measured in an electric machinery company. The blade is fixed in the slot of cluster cradles. The Flir T250 thermal imaging camera is employed for real-time measuring the temperature field, whose

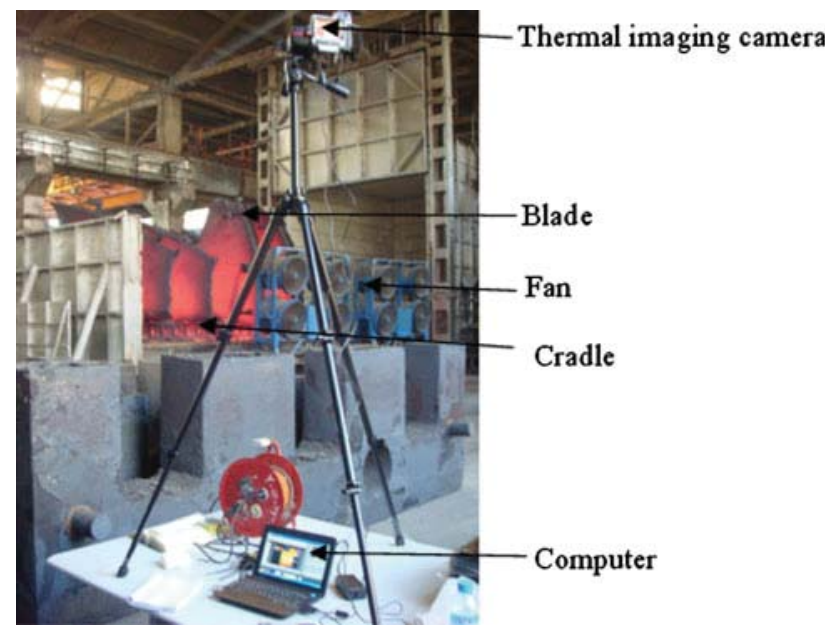

Fig. 1 Testing temperature field of blade by using the Flir T250 thermal imaging camera error is $2{ }^{\circ} \mathrm{C}$, as shown in Fig. 1. A kind of deformation measurement instrument is employed for real-time testing the distortion behavior, whose error is $2 \mathrm{~mm}$. The distortion behavior at both $\mathrm{Sp} 1$ and $\mathrm{Sp} 2$ was measured, as shown in Fig. 2. The Sp1 locates at the blade corner in the outlet edge, whose distortion from the front direction and the back direction are measured, respectively. The Sp2 locates at the blade corner in the inlet edge. The forced air cooling is employed in the normalizing process, and the exit air speed is about $10 \mathrm{~m} / \mathrm{s}$.

The maximum boundary dimensions of blade is $4720 \times 3340 \times 200 \mathrm{~mm}$, and the blade thickness from the inlet edge to the outlet edge are 200-40 $\mathrm{mm}$. The gross weight of a blade without riser is 17 ton. The material of blade is ZG0Cr13Ni4Mo, whose main chemical components are shown in Table 1.

\section{Results and Discussion}

Figure 3(a) shows the distortion at $\mathrm{Sp} 1$ after tapping off the furnace, where the positive value means that the distortion direction is along the front direction measured from the blade front side or along the back direction measured form the blade back side (The directions are shown in Fig. 2). In the figure, the distortion at $\mathrm{Sp} 1$ from the front direction is in good complementary with that from the back direction, which means the experimental results are dependable and the method for measuring the distortion of blade demonstrates practicability. Two peaks and a valley appear in the blade distortion process. The first peak appears after 80 min of cooling, the valley appears after 200-220 min of cooling, and the second peak appears after 500-520 min of cooling. Figure 3(b) shows the distortion at $\mathrm{Sp} 2$ measured from the blade front side. In the figure, the maximum distortion is about $20 \mathrm{~mm}$, and the final distortion is less than $10 \mathrm{~mm}$. Compared the distortion at Sp2 with that at $\mathrm{Sp} 1$, the distortion at $\mathrm{Sp} 2$ could be neglected. Hence, the distortion at $\mathrm{Sp} 1$ could reflect the maximum distortion of blade. For analytical convenience, only the

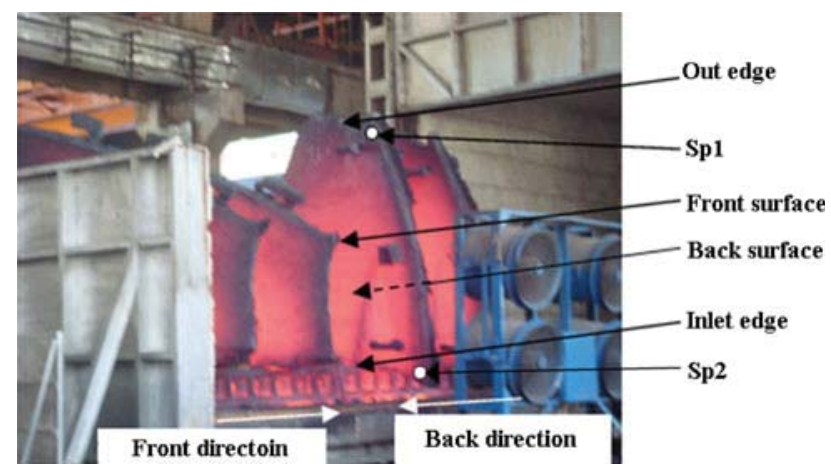

Fig. 2 Testing distortion of the blade during forced air cooling

Table 1 Main chemical components of ZG0Cr13Ni4Mo (mass\%)

\begin{tabular}{ccccccccc}
\hline $\mathbf{C}$ & $\mathbf{S i}$ & $\mathbf{M n}$ & $\mathbf{P}$ & $\mathbf{S}$ & $\mathbf{N i}$ & $\mathbf{C r}$ & $\mathbf{M o}$ & $\mathbf{C u}$ \\
\hline 0.03 & 0.46 & $0.52-0.55$ & 0.011 & $0.012-0.025$ & 4.25 & $13.46-13.61$ & $0.60-0.65$ & $0.08-0.09$ \\
\hline
\end{tabular}



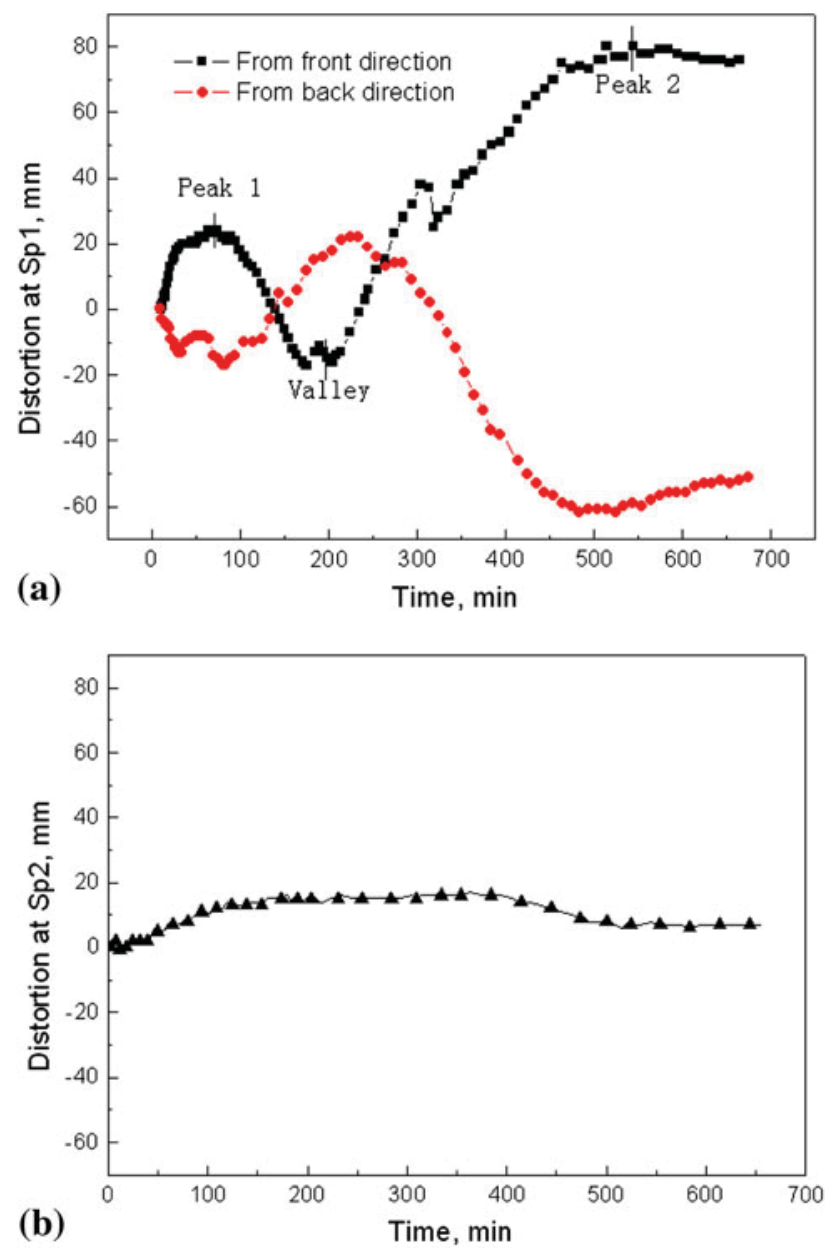

Fig. 3 Distortion of blade at Sp1 (a) and Sp2 (b) during air forced cooling in normalizing process

distortion at $\mathrm{Sp} 1$ measured from the front surface was analyzed in the following.

Figure 4 shows the temperature field of blade at different stages. The tapping furnace is $1020^{\circ} \mathrm{C}$, and the maximum temperature drops to $920^{\circ} \mathrm{C}$ after about a minute of tapping operation time. After cooling $80 \mathrm{~min}$, the maximum temperature drops to $640{ }^{\circ} \mathrm{C}$. After 220 min of cooling, the maximum temperature drops to $475{ }^{\circ} \mathrm{C}$, and the maximum temperature drops to $285^{\circ} \mathrm{C}$ after $510 \mathrm{~min}$ of cooling, and the cooling speed is low in this period.

In the forced air cooling process, the maximum temperature was employed to control the cooling time that the forced air cooling could be closed when it is lower than the end temperature of martensite. In Fig. 4, the maximum temperature generally appears in the zone near the inlet edge and the cradle. Figure 5 summarizes the cooling curves of the maximum temperature and the temperature at $\mathrm{Sp} 1$. At $\mathrm{Sp} 1$, the temperature is $276{ }^{\circ} \mathrm{C}$ after $47 \mathrm{~min}$ of cooling, and it drops to $167{ }^{\circ} \mathrm{C}$ after 80 min of cooling that the temperature drop is $830^{\circ} \mathrm{C}$, the temperature is $80{ }^{\circ} \mathrm{C}$ after 220 min of cooling and the speed of temperature drop gradually decreases in following, and $50{ }^{\circ} \mathrm{C}$ for after $325 \mathrm{~min}$ of cooling, and $33{ }^{\circ} \mathrm{C}$ for after $510 \mathrm{~min}$ of cooling which closes to the ambient temperature. After $530 \mathrm{~min}$ of cooling, the maximum temperature on blade reaches $276{ }^{\circ} \mathrm{C}$. In the following, the temperature at $\mathrm{Sp} 1$ is considered as the minimum temperature.
During forced air cooling process, the shrinkage deformation of blade is generally non-uniform because of the temperature difference in blade caused by the disparity of wall thickness and the different boundary heat transfer conditions, which results in great thermal stress in the blade. Simultaneously, the martensitic transformation begins in different zones at different time on account of the uneven temperature distribution, which results in large transformation stress in blade. Therefore, the distortion might appear in blades under the action of thermal stress and transformation stress, which is an assembling of volume change and shape distortion. The total strain consists of thermal strain, elastic strain, classical plastic strain, transformation strain, and transformation plasticity strain, as shown in Eq 1 (Ref 12-14).

$\varepsilon_{i j}=\varepsilon_{i j}^{\mathrm{th}}+\varepsilon_{i j}^{\mathrm{e}}+\varepsilon_{i j}^{\mathrm{cp}}+\varepsilon_{i j}^{\mathrm{tr}}+\varepsilon_{i j}^{\mathrm{tp}}$,

where

$\varepsilon_{i j}^{\text {th }}=\breve{\alpha}(T, \xi) \Delta T \delta_{i j}$

$\varepsilon_{i j}^{\mathrm{e}}=\frac{1}{\breve{E}(T, \xi)}\left[(1+\breve{v}(T, \xi)) \sigma_{i j}-\delta_{i j} \breve{v}(T, \xi) \sigma_{\mathrm{m}}\right]$

$\varepsilon_{i j}^{\mathrm{cp}}=\frac{\sigma_{i j}-\sigma_{s 0}(T, \xi)}{H_{\mathrm{P}}(T, \xi)}$

$\varepsilon_{i j}^{\mathrm{tr}}=\beta(T) \xi \delta_{i j}$

$\varepsilon_{i j}^{\mathrm{tp}}=K \xi(2-\xi) \sigma_{i j}$

where $\varepsilon_{i j}$ is total strain, $\varepsilon_{i j}^{\text {th }}$ is thermal strain, $\varepsilon_{i j}^{\mathrm{e}}$ is elastic strain, $\varepsilon_{i j}^{\mathrm{cp}}$ is classical plastic strain, $\varepsilon_{i j}^{\mathrm{tr}}$ is transformation strain, $\varepsilon_{i j}^{\mathrm{tp}}$ is transformation plasticity strain, $\delta_{i j}$ is Kronecker delta, $T$ is temperature, $\xi$ is volume fraction of a phase (in the article, it is the volume fraction of martensite), $\alpha(T, \xi)$ is coefficient of equivalent thermal expansion, $\breve{E}(T, \xi)$ is equivalent elastic modulus of material with mixed phases, $\breve{v}(T, \xi)$ is equivalent Poisson's ratio of material with mixed phases, $\sigma_{i j}$ is component of stress, $\sigma_{\mathrm{m}}$ is hydrostatic stress, $\sigma_{s 0}(T, \xi)$ is initial yield stress, $H_{\mathrm{P}}(T, \xi)$ is plastic modulus, $\beta(T)$ is coefficient of phase transformation expansion, and $K$ is coefficient of transformation plasticity.

During forced air cooling process of the ZG0Cr13Ni4Mo martensitic stainless steel, the austenite directly transfers into the martensite (Ref 15,16$)$, and the martensitic transformation beginning point (Ms point) is $276{ }^{\circ} \mathrm{C}$ (Ref 14). Figure 6 shows distortion, distortion velocity, temperature difference, cooling rate in blade during cooling, which is divided into A1-A5 periods. In the following, the main influencing factors and the stress distribution in different periods on the distortion of blade are analyzed. The equivalent stress distributions in blade at different time are obtained through the finite element analysis, as shown in Fig. 7, which could shows the possible deformation regions in normalizing process. In the FE model, the Young's modulus, deformation resistance, tangent modulus are related to the temperature, strain rate, etc., which are obtained in Ref 17 ; the transformation plasticity is set as $8.74 \times 10^{-5}$ / $\mathrm{MPa}$ (Ref 14); and the heat transfer coefficients, the coefficient of thermal expansion are obtained in Ref 14.

In Fig. 5, the minimum temperature of blade is higher than Ms point before $47 \mathrm{~min}$ of cooling. Hence, only $\varepsilon_{i j}^{\text {th }}, \varepsilon_{i j}^{\mathrm{e}}$, and $\varepsilon_{i j}^{\mathrm{cp}}$ occur in the period, and $\varepsilon_{i j}^{\text {th }}$ plays a dominant role in the distortion 


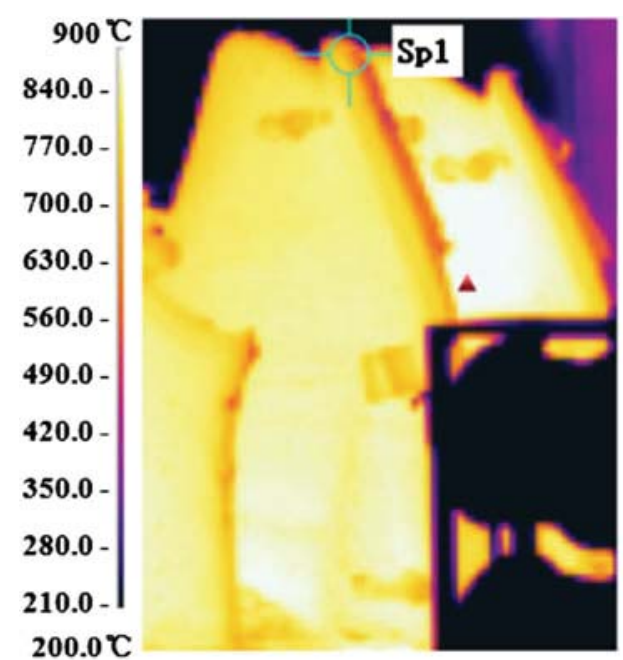

(a)

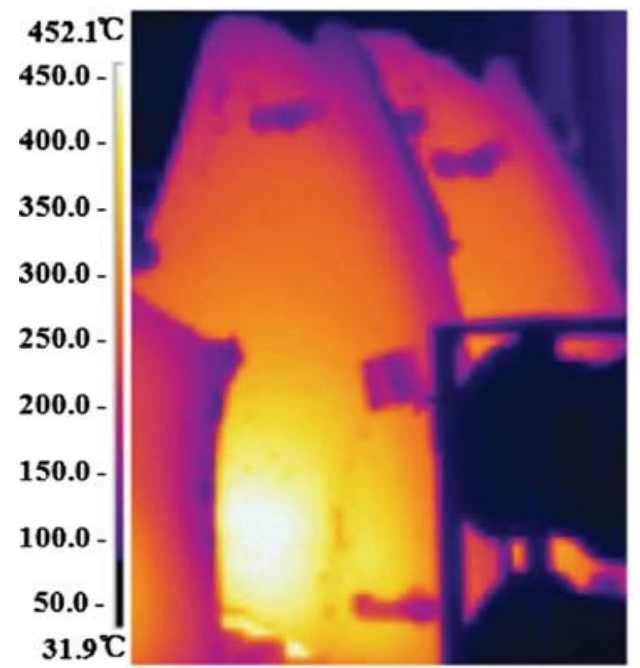

(c)

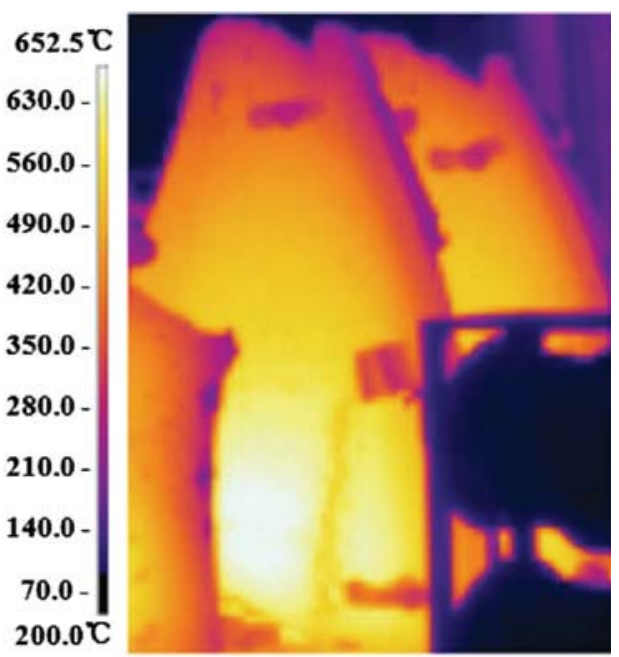

(b)

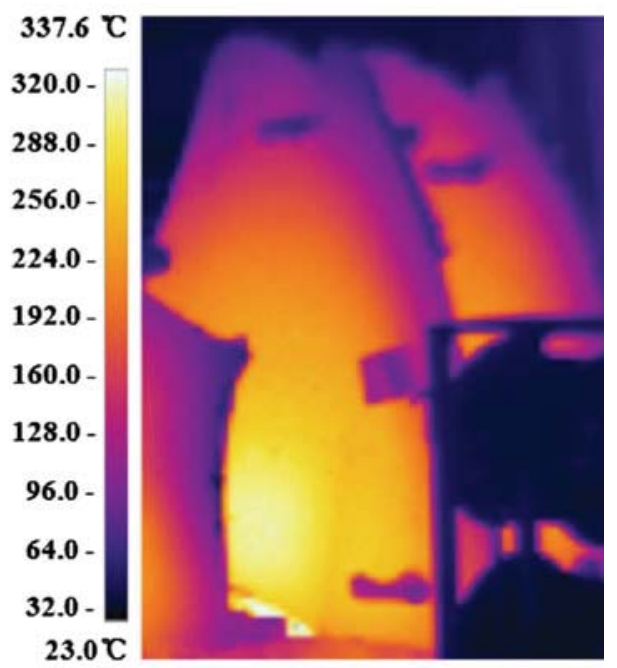

(d)

Fig. 4 Temperature fields of the blade after $1 \mathrm{~min}$ (a), $80 \mathrm{~min}$ (b), $220 \mathrm{~min}$ (c), and $510 \mathrm{~min}$ (d) of cooling

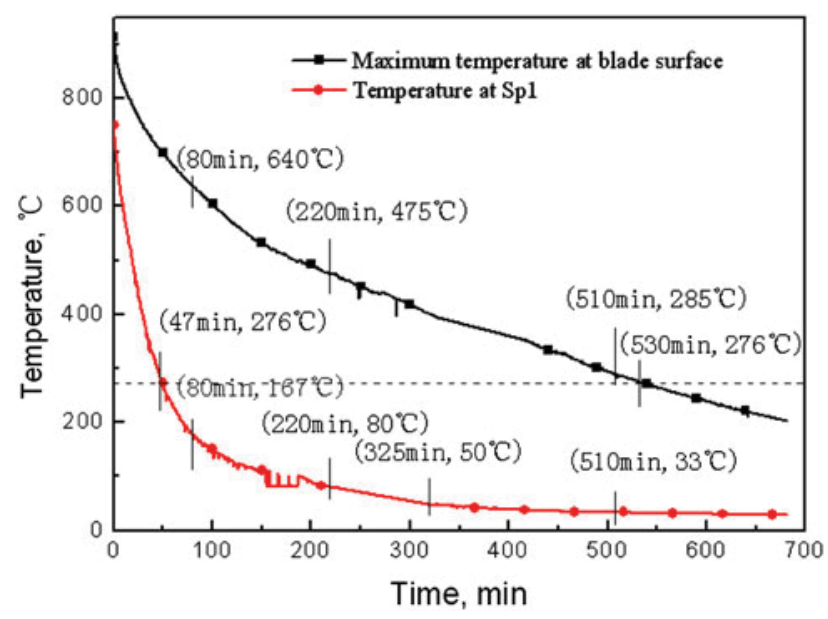

Fig. 5 Cooling curves during air forced cooling

process. Given that the blade microstructure is only austenite whose deformation resistance is small, the distortion is susceptible to occur under the action of small stress station. Figure 2 shows the arrangement of blades and fans. The back side of the blade faces the wind blowing, so the temperature drop on the back surface is greater than that of the front surface, according to Eq $2, \varepsilon_{\mathrm{B}}^{\text {th }}>\varepsilon_{\mathrm{F}}^{\text {th }}$, where $\varepsilon_{\mathrm{B}}^{\text {th }}$ for $\varepsilon_{i j}^{\text {th }}$ of back surface, $\varepsilon_{\mathrm{F}}^{\text {th }}$ is $\varepsilon_{i j}^{\text {th }}$ of front surface. Hence, the distortion direction at blade corner is along the front direction in the period. Owing to $\varepsilon_{\mathrm{B}}^{\text {th }}>\varepsilon_{\mathrm{F}}^{\text {th }}$, tensile stress will appear in the front side, which gradually increases with increasing the difference between $\varepsilon_{\mathrm{B}}^{\text {th }}$ and $\varepsilon_{\mathrm{F}}^{\text {th }}$. Figure $7(\mathrm{~b})$ shows the equivalent stress distribution after $30 \mathrm{~min}$ of cooling. The stress near blade corner in front side is greater than that in back side. The tensile stress will result in $\varepsilon_{i j}^{\mathrm{e}}$ and $\varepsilon_{i j}^{\mathrm{cp}}\left(\varepsilon_{i j}^{\mathrm{cp}}\right.$ might be zero) for counteracting the $\varepsilon_{i j}^{\text {th }}$, so the distortion velocity gradually decreases. In Fig. 6(b), the distortion velocity at $\mathrm{Sp} 1$ reaches $1.5 \mathrm{~mm} / \mathrm{min}$ when the blade is tapped off the furnace, which gradually decreases in the A1 period.

The temperature difference in blade gradually increases until 80 min of cooling, which reaches the maximum temperature difference of $470{ }^{\circ} \mathrm{C}$, as shown in Fig. 6(c). At the time, the first peak of distortion appears, as shown in Fig. 6A2. With increasing the temperature difference, the stress in blade increases, but the difference of the stress distribution between the blade front and the blade back decreases, as shown in 


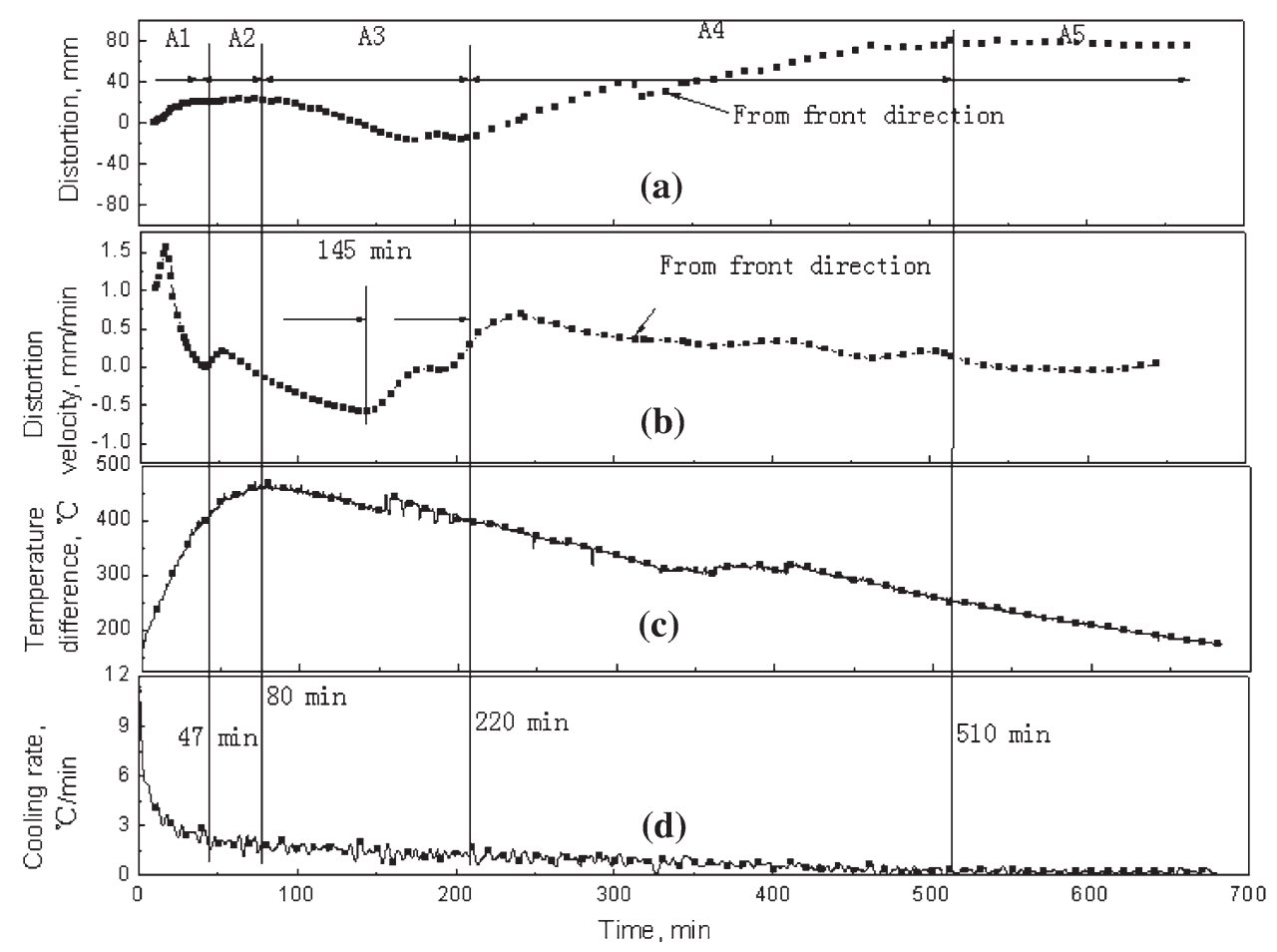

Fig. 6 Comparison of distortion, distortion velocity, temperature difference, cooling rate curves of the blade

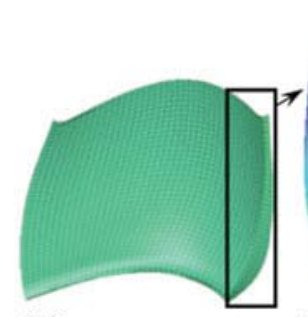

(a)

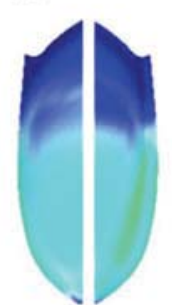

(d)

(e)

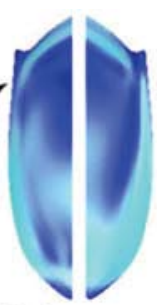

(b)

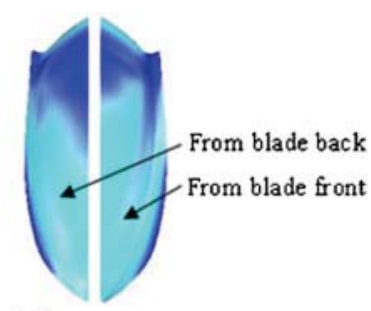

(c)

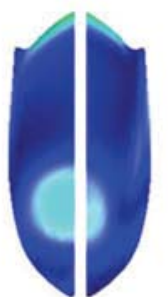

(f)

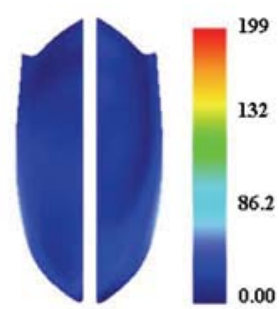

(f)

Fig. 7 FE meshing of blade (a) and stress distribution (MPa) in blade after $30 \mathrm{~min}(\mathrm{~b}), 60 \mathrm{~min}(\mathrm{c}), 150 \mathrm{~min}(\mathrm{~d}), 300 \mathrm{~min}(\mathrm{e})$, and $600 \mathrm{~min}(\mathrm{f})$ of cooling

Fig. 7(c). In this period, the martensitic transformation begins at the edge of blade. As the temperature at the blade back is lower than that at the blade front, so, the transformation deformation in blade back will be greater than that at the blade front. Meanwhile, the martensitic transformation is expansive, which results in the blade distortion in the direction contrary to that caused by $\varepsilon_{i j}^{\text {th }}$. However, the transformation deformation only occurs in the outlet edge because the temperature in most regions is still greater than the Ms point, which slightly affects the distortion of blade. Hence, in this period, the $\varepsilon_{i j}^{\text {th }}$ still plays the dominant role. With increasing $\Delta \varepsilon_{i j}^{\text {th }}, \varepsilon_{i j}^{\text {e }}$ and $\varepsilon_{i j}^{\mathrm{cp}}$ increase.

Under the integrated action of $\varepsilon_{i j}^{\mathrm{th}}, \varepsilon_{i j}^{\mathrm{e}}, \varepsilon_{i j}^{\mathrm{cp}}$, and $\varepsilon_{i j}^{\mathrm{tr}}$, the distortion of blade slightly increases along the front direction, but the distortion velocity is slight which fluctuates about $0 \mathrm{~mm} / \mathrm{min}$, as shown in Fig. 6(b).

The temperature difference in blade gradually decreases after 80 min of cooling, as shown in Fig. 6(c). Meantime, the temperature difference between the blade front and the blade back decreases with increasing the distortion of blade along front direction, so the difference between $\Delta \varepsilon_{\mathrm{B}}^{\text {th }}$ and $\Delta \varepsilon_{\mathrm{F}}^{\text {th }}$ gradually decreases. At the same time, $\varepsilon_{i j}^{\mathrm{e}}$ gradually decreases with decreasing the temperature difference and with increasing the elastic modulus of material, which results in the blade deforming along the back direction. The increment of $\varepsilon_{i j}^{\mathrm{cp}}$ will reduce with increasing the deformation resistance of blade. However, the phase transformation zone near the outlet edge gradually increases. After 220 min of cooling, the zone with the temperature below the Ms point gets larger, where the martensitic transformation begins, as shown in Fig. 8(a). In this period, the transformation deformation at blade back will be greater than that at blade front, because of the temperature of the blade back is lower than that of the blade front. With further decreasing of temperature, the difference between the transformation deformation at blade back and that at blade front gradually increases. Figure 7(d) shows the stress distribution in blade after 150 min of cooling. At the time, the equivalent stress in blade front is less than that in blade back. In this period, the distortion behavior is affected by $\varepsilon_{i j}^{\mathrm{th}}, \varepsilon_{i j}^{\mathrm{e}}, \varepsilon_{i j}^{\mathrm{cp}}, \varepsilon_{i j}^{\mathrm{tr}}$, and $\varepsilon_{i j}^{\mathrm{tp}}$, where the increment of $\varepsilon_{i j}^{\text {th }}$ increases slightly with low cooling rate, $\varepsilon_{i j}^{\mathrm{cp}}$ and $\varepsilon_{i j}^{\mathrm{tr}}$ mainly appear near the blade edge whose influence on the distortion of blade is slight, and $\varepsilon_{i j}^{\mathrm{e}}$ and $\varepsilon_{i j}^{\mathrm{tr}}$ play the dominant role whose direction is along the back direction. Hence, the direction of distortion is along the back direction.

When the cooling time exceeds $220 \mathrm{~min}$, the distortion direction at blade corner is reverted into the front direction, and the valley of distortion appears. In Fig. 6(b), the distortion 


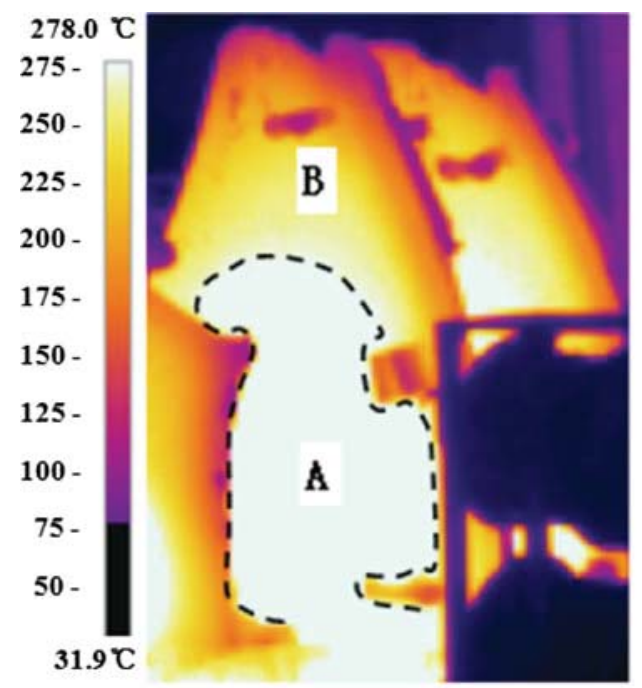

(a)

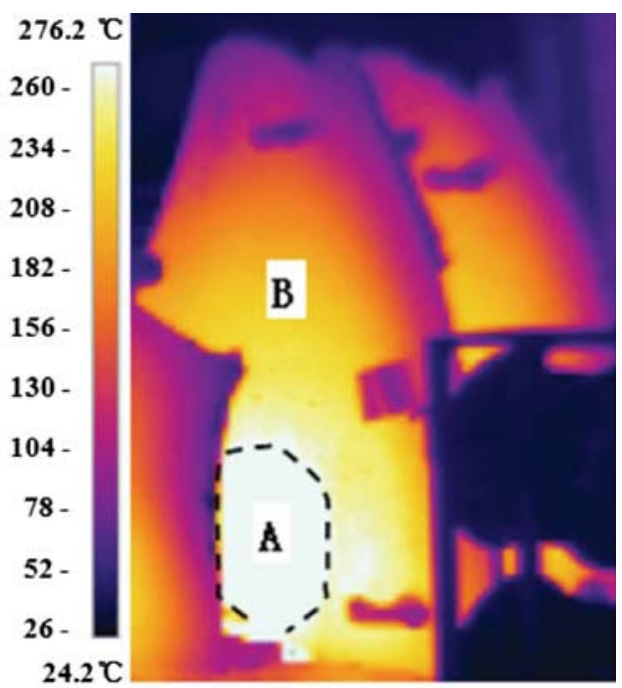

(b)

Fig. 8 Phase transfer zone in blade after cooling $220 \mathrm{~min}$ (a), and $510 \mathrm{~min}$ (b), where zone A is the austenitic zone and zone B is the martensite transformation zone

velocity along the front direction gradually increases and maintains a long period. The martensitic transformation in the blade front is less than that in the blade back in the A3 period. In the A4 period, the increment of $\varepsilon_{\mathrm{F}}^{\mathrm{tr}}$ comes to be gradually greater than the increment of $\varepsilon_{\mathrm{B}}^{\mathrm{tr}}$, which makes the blade deform along the front direction. At the time, the deformation resistance of blade becomes stronger, and the blade back will bear large compressive stress when the blade deforms along the front direction. Figure 7(e) shows stress distribution in blade after $300 \mathrm{~min}$ of cooling, and the stress in the central zone of blade back is larger than that of blade front. The stress might induce the martensitic transformation plasticity. The transformation plasticity (Ref 12,13 ) is caused by the non-uniform thermal distribution and phase transformation in heat treatment process, and the transformation plasticity is irreversible. In Eq $6, \varepsilon_{i j}^{\mathrm{t}}$ depends on the stress, which makes the blade deform along the front direction. Meanwhile, $\varepsilon_{i j}^{\text {th }}$ and $\varepsilon_{i j}^{\mathrm{e}}$ still make the blade deform along the back direction with decreasing the temperature difference and the temperature. $\varepsilon_{i j}^{\mathrm{cp}}$ could be neglected for the transformation plasticity. Meanwhile, as shown in Fig. 8, controlling the phase transformation in the zones of complementary set between " $A$ " in (a) and (b) is very significant for controlling the distortion of blade.

When the cooling time exceeds $510 \mathrm{~min}$, the phase transformation mainly occurs in the symmetrical regions near the inlet edge side of blade, as shown in Fig. 8(b). With decreasing the cooling rate, the effects of the phase transformation and the thermal deformation on the distortion at blade corner comes to be very slight. Figure 7(f) shows the stress distribution in blade after 600 min of cooling, and the stress in the blade is slight. And with decreasing the temperature and the temperature difference, there still is slight distortion, as shown in Fig. 6A5.

In the measured results, the distortion at $\mathrm{Sp} 1$ is great. In the A4 period, the distortion reaches $97 \mathrm{~mm}$. After $660 \mathrm{~min}$ of cooling, the distortion of blade compared with that leaving the furnace is $76 \mathrm{~mm}$. As described in Sect. 1, the distortion of blade will severely affect the blade quality and the following processes. Mastering and controlling the distortion behavior is the aims in production for reducing the processes of shape righting, reducing the machining allowance, etc.

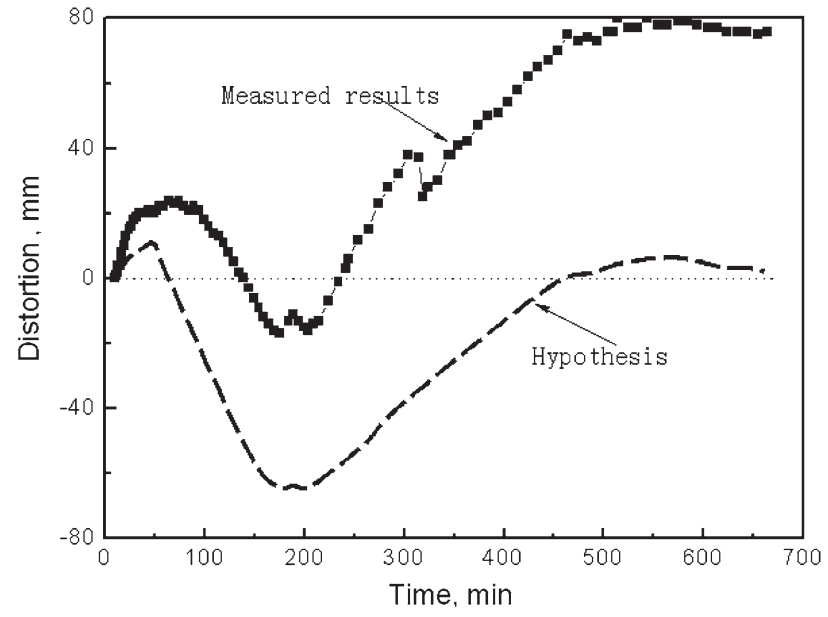

Fig. 9 Schemes for controlling distortion of blade

A hypothesis for controlling the distortion behavior of blade is proposed for reducing the distortion of blade focusing on the measured result, as shown in Fig. 9. The control idea at every period is as follows. (1) Reducing the distortion of blade along the front direction in the $\mathrm{A} 1$ and $\mathrm{A} 2$ periods. In these periods, the distortion is mainly caused by $\varepsilon_{i j}^{\mathrm{th}}, \varepsilon_{i j}^{\mathrm{e}}$, and $\varepsilon_{i j}^{\mathrm{cp}}$, which are affected by the temperature field and the cooling rate. Hence, only cooling the blade uniformly and reducing the cooling speed, the distortion of blade could be reduced. (2) Improving the distortion of blade along the back direction in the A3 period. In this period, the distortion of blade is affected by $\varepsilon_{i j}^{\text {th }}$, $\varepsilon_{i j}^{\mathrm{e}}, \varepsilon_{i j}^{\mathrm{cp}}, \varepsilon_{i j}^{\mathrm{tr}}$, and $\varepsilon_{i j}^{\mathrm{tp}}$. Where, $\varepsilon_{i j}^{\mathrm{e}}$ and $\varepsilon_{i j}^{\mathrm{cp}}$ increase with decreasing the temperature difference. Making the martensitic transformation in blade back first, and expanding the martensitic zone in blade back, the distortion of blade will increase along the back direction with increasing $\varepsilon_{i j}^{\mathrm{tr}}$ and $\varepsilon_{i j}^{\mathrm{tp}}$. It is obvious that it will result in the non-uniform of temperature field and will make against of controlling blade properties. (3) Reducing the distortion of blade along the front direction in the A4 period. In this period, $\varepsilon_{i j}^{\mathrm{tr}}$ and $\varepsilon_{i j}^{\mathrm{tp}}$ are leading the distortion of blade, and 
$\varepsilon_{i j}^{\mathrm{tp}}$ is direct ratio to the stress in blade. The martensitic transformation occurs in most regions in the outlet side. Through reducing the temperature drop velocity and the stress in blade, $\varepsilon_{i j}^{\text {tp }}$ could be effectively decreased, and then the distortion of blade along the front direction could be reduced. (4) For the distortion of blade in the A5 period, it is just affected by the temperature and the temperature difference, and its influence on the distortion of blade is slight. From the analysis above, in actual production, the control of the distortion of blade could be trued through suitable controlling the cooling speed according to the need of ideal blade shape. It must be proposed especially that the control of A4 period is of significance for controlling the distortion of blades.

\section{Conclusions}

(1) The real-time measurements on the distortion behavior and the temperature field of a heavy hydro turbine blade casting during forced air cooling in normalizing treatment process were originally carried out by experimental methods, which give a way for studying and controlling the distortion behavior of heavy casting in production.

(2) Two peaks and a valley appear in the distortion process at blade corner in the outlet edge side during forced air cooling in normalizing treatment process, and the distortion range reaches $97 \mathrm{~mm}$.

(3) In the experimental setting, the maximum temperature difference reaches $460{ }^{\circ} \mathrm{C}$ after $80 \mathrm{~min}$ of cooling caused by the thickness difference between the inlet and the outlet edges.

(4) There is large distortion at the blade corner in outlet edge side from cooling 220 to $510 \mathrm{~min}$ for the non-uniform distribution of temperature and phase transformation. Controlling the cooling speed and the phase transformation at this stage is very important for controlling the distortion behavior.

\section{Acknowledgments}

The authors gratefully acknowledge the financial supports from the National Eleventh Five-Year Science and Technology Support Program of China through Grant No. 2007BAF02B07, and the State Basic Research Key Projects (973) of China through Grant No. 2005 CB724105.

\section{References}

1. J.W. Kang, T.Y. Huang, and B.C. Liu, Review of Production Status of Heavy Steel Castings and Key Technologies for Their Manufacture in China, China Foundry, 2008, 5(1), p 1-6

2. F. Liang, Mono-Block Casting Process of Stainless-Steel Blade Used in Large-Size Mixed Flow Turbine, Foundry, 2001, 50(5), p 285-287

3. Y. Wu, Study on the Casting Process of the Three Gorges Turbine Blade, Large Electr. Mach. Hydraul. Turbine, 2009, 4, p 39-41, 54

4. F.Y. Li and Q.Y. Wang, Technical Measures to Improve Casting Accuracy of Blades, Power Syst. Eng., 2007, 23(2), p 71-72

5. B.C. Liu, J.W. Kang, and S.M. Xiong, A Study on the Numerical Simulation of Thermal Stress During the Solidification of Shaped Castings, Sci. Technol. Adv. Mater., 2001, 2, p 157-164

6. J.F. Zhang, J.W. Kang, B.C. Liu, Y. Wu, J.S. Zhang, Z.C. Rong, and C.C. Zhang, Numerical Simulation of Deformation in Large Scale Hydroturbine Blade Casting, Int. J. Cast Met. Res., 2008, 21(1-4), p 304-307

7. S.M. Lee and W.J. Lee, Finite-Element Analysis on Thermomechanical Behavior of a Marine Propeller Casting in the Sand-Casting Process, J. Mater. Eng. Perform., 2005, 14(3), p 388-394

8. S. Bruschi and A. Ghiotti, Distortions Induced in Turbine Blades by Hot Forging and Cooling, Int. J. Mach. Tools Manuf., 2008, 48(7-8), p 761-767

9. D. Zhang, W.H. Zhang, M. Wan, J.F. Wang, and K. Bu, Reversing Design Methodology of the Die Profile in Investment Casting Based on the Simulation of Displacement Field and Identification of Featured Parameters, Acta Aeronaut. Astronaut. Sin., 2007, 27(3), p 509-514

10. C.W. Geng, S.S. He, and B. Yu, Investigation on ZG0Cr13Ni4Mo Stainless Steel, Phys. Exam. Test., 1992, 4, p 13-25

11. S.F. Zhou, Y.C. Wang, X.Y. Li, B.J. Zhou, B. Li, and W.D. Li, Microstructure and Mechanical Properties in Simulated HAZ of 0Cr13Ni4Mo Martensitic Stainless Steel, Trans. China Weld. Inst., 2004, 25(4), p 63-66

12. M. Coret and A. Combescure, A Mesomodel for the Numerical Simulation of the Multiphasic Behavior of Materials Under Anisothermal Loading, Int. J. Mech. Sci., 2002, 44(9), p 1947-1963

13. C.Y. Sun, G. Fang, L.P. Lei, and P. Zeng, Numerical Simulation of Metal Quenching With Consideration of Influence of Temperature and Phase Transformation, Trans. Mater. Heat Treat., 2008, 29(1), p 162166

14. R. Zhang, Stress Analysis and Deformation Prediction of Hydraulic Turbine Blade for Three Gorges Project in Heat Treatment Process. Thesis of Tsinghua University, NY, 2009

15. L.B. Sun, Q.Y. Xu, and B.C. Liu, Numerical Simulation of Phase Transformation of ZG0Cr13Ni4Mo Stainless Steel Casting, Acta Metall. Sin., 2003, 39(4), p 387-394

16. L.B. Sun, Q.Y. Xu, B.C. Liu, Numerical Simulation of Phase Transformation and Microstructure of ZG0Cr13Ni4Mo Stainless Steel Casting, Modelling of Casting, Welding and Advanced Solidification Processes- $X$, May 2003, p 157-164

17. R. Zhang, J.W. Kang, T.Y. Huang, B.C. Liu, and Y.Y. Hu, Mechanical Properties of Martensite Stainless Steel at High Temperature, Foundry Technol., 2009, 30(10), p 1252-1255 